\title{
Uso de substâncias, situações de risco e soroprevalência em indivíduos que buscam testagem gratuita para HIV em Porto Alegre, Brasil
}

\author{
Flavio Pechansky, ${ }_{1}^{1}$ Felix Kessler, ${ }^{1}$ Lísia Von Diemen, ${ }^{1}$ \\ James A. Inciardi ${ }^{2}$ e Hilary Surratt ${ }^{2}$
}

Como citar Pechansky F, Kessler F, Von Diemen L, Inciardi JA, Surratt H. Uso de substâncias, situações de risco e soroprevalência em indivíduos que buscam testagem gratuita para HIV em Porto Alegre, Brasil. Rev Panam Salud Publica. 2005;18(4/5):249-55.

RESUMO Objetivo. Descrever o uso de substâncias, a soroprevalência e a presença de situações de risco para infecção por HIV em indivíduos que buscaram testagem sorológica em um centro municipal e em um centro estadual de testagem e aconselhamento na Cidade de Porto Alegre (RS), Brasil. Método. Através de um delineamento transversal, foi obtida uma amostra de conveniência de 1026 homens e mulheres com idade entre 15 e 60 anos. Foram incluídos todos os indivíduos que, após uma triagem inicial, descreviam qualquer uso de droga ou qualquer comportamento ou situação de risco para a transmissão do HIV. Para avaliar a exposição a situações de risco, utilizou-se o questionário de comportamento de risco para AIDS, uma versão do risk assessment battery (RAB) traduzida para o português brasileiro. As amostras de sangue foram testadas para anticorpos anti-HIV usando o método imunoenzimático (ELISA). Antes do exame, cada indivíduo participava de uma sessão de aconselhamento em grupo (máximo de 20 participantes) sobre HIV e AIDS, de acordo com os critérios do Ministério da Saúde do Brasil.

Resultados. A taxa de soropositividade para a amostra em geral foi alta, de 15,1\%. O uso de substâncias não explicou toda a exposição ao risco; o uso de drogas injetáveis ao longo da vida, apesar de apresentar uma razão de chances (OR) de 7,6 (IC95\% = 4,4 a 13,0) para soropositividade, esteve presente em apenas 10,3\% das respostas. Gênero masculino (OR $=1,8 ;$ IC95\% = 1,1 a 2,8), renda familiar inferior a 3 salários minimos por mês $(O R=2,1 ; I C 95 \%=1,3$ a 3,5), idade acima de 25 anos (OR =1,7; IC95\% =1,1 a 2,7) e ter tido relação sexual com possível indivíduo soropositivo $(O R=1,8 ;$ IC95\% = 1,1 a 3,2) estiveram associados com soropositividade. Conclusões. Mesmo o uso não regular ou sistemático de substâncias, em especial sob forma endovenosa, aumenta as chances de soropositividade. A transmissão sexual teve um papel importante na soropositividade nesta amostra, indicando que a diminuição do senso crítico pelo uso de drogas pode comprometer a avaliação de situações de risco e contribuir para a transmissão do HIV.

Palavras-chave Abuso de substâncias por via endovenosa, epidemiologia,síndrome de imunodeficiência adquirida.

1 Universidade Federal do Rio Grande do Sul (UFRGS), Centro de Pesquisa em Álcool e Drogas, Brasil. Enviar correspondência para Flavio Pechansky no seguinte endereço: Centro de Pesquisa em Álcool e Drogas da UFRGS, Rua Ramiro Barcelos 2350, sala $2201 \mathrm{f}$, CEP 90035-003, Porto Alegre, RS, Brasil. E-mail: cpad.fm@uol.com.br
2 University of Delaware, Center for Drug and Alcohol Studies, Newark, Delaware, Estados Unidos. 
Os casos de AIDS no Brasil aumentaram de forma dramática desde a década de 1990. Atualmente, o país ocupa o segundo lugar em número de casos oficialmente relatados (1). De acordo com o Ministério da Saúde, a incidência média global de casos de AIDS no Brasil é de 14,1 em 100000 habitantes/ano (2), com cerca de 360000 casos relatados desde o início da epidemia (3).

As mais altas taxas de incidência são registradas para os estados de São Paulo, Rio de Janeiro e Rio Grande do Sul. Porto Alegre, capital do Rio Grande do Sul e quinta maior cidade brasileira, totalizava 3,5\% dos casos do país, com a terceira mais alta taxa de incidência em 2000 (90 em 100000 habitantes) (3).

Um dos modos significativos de transmissão do HIV em Porto Alegre é o abuso de drogas. Pechansky e Von Diemen (4) reportaram, em 1999, que $44 \%$ dos usuários de drogas injetáveis (UDIs) que buscavam atendimento em um centro público eram soropositivos. Nesse estudo, quando os resultados foram reanalisados excluindo-se os UDIs, a taxa de infecção nos usuários de drogas em geral caiu para 16\% (5). Outro estudo (6) relatou uma prevalência de infecção por HIV em UDIs de $54,5 \%$ no ano de 2000 . Um relatório divulgado em 2002 (7) aponta a Região Sul como tendo a maior prevalência de uso alguma vez na vida de qualquer droga exceto álcool e tabaco $(17,1 \%)$, maior dependência de maconha $(1,6 \%)$ e maior prevalência de uso na vida de maconha $(8,4 \%)$ e cocaína $(3,6 \%)$. Nos últimos anos, tem havido uma tendência à redução na transmissão sexual do HIV entre os homens que fazem sexo com homens, que representavam $31,4 \%$ dos casos na primeira década da infecção e hoje são responsáveis por apenas 6,2\% (8).

Entretanto, ainda $25 \%$ dos casos de AIDS diagnosticados parecem estar direta ou indiretamente relacionados ao uso de drogas injetáveis: Watkins (9) identificou que $38,2 \%$ das mulheres com diagnóstico de AIDS relataram haver contraído o vírus de um UDI. Um estudo da Organização Mundial da Saúde (OMS) com 6390 UDIs revelou uma taxa de $25 \%$ de compartilha- mento freqüente de seringas. Nos 85 UDIs entrevistados em Santos, Brasil, para esse estudo, a taxa geral de soroprevalência foi de $60 \%$ (10).

Estudos com foco em abusadores e dependentes de drogas desconsideram que a transmissão do vírus pode ocorrer também em usuários não-sistemáticos e que haja diferença entre gêneros associada a essa nãosistematicidade (11). Em nosso meio, ainda existem poucos estudos que avaliam as situações de risco para a transmissão do HIV entre indivíduos que usam drogas-seja de forma sistemática, recreacional, ou eventual. $\mathrm{O}$ presente estudo busca contribuir para a compreensão desse fenômeno complexo através da análise de situações de risco e de soroprevalência em uma amostra de indivíduos que buscaram testagem para HIV em centros de triagem, aconselhamento e tratamento na Cidade de Porto Alegre.

\section{SUJEITOS E MÉTODOS}

Foi realizado um estudo transversal com uma amostra de conveniência de 1436 voluntários de ambos os sexos, com idade variando entre 15 e 60 anos, durante aproximadamente 20 meses entre 1995 e 1997. Todos os indivíduos que concordaram em participar do estudo e que tinham o resultado do exame anti-HIV disponível foram incluídos.

Para a coleta de dados foram treinados 15 entrevistadores, todos profissionais com nível de graduação ou estudantes da área médica. Os locais para a coleta foram o Centro de Testagem e Aconselhamento (CTA) Paulo César Bonfim, da Prefeitura Municipal de Porto Alegre, e o CTA estadual. Os CTAs oferecem testagem gratuita e anônima para HIV. Foram excluídos da amostra 50 indivíduos para quem não foi possível obter o resultado do teste anti-HIV. O número final de casos para fins de análise foi de 1026 indivíduos, sendo 236 (23\%) do CTA estadual e 790 (77\%) do municipal.

$\mathrm{O}$ instrumento utilizado para avaliar a exposição a situações de risco para a transmissão do HIV nos usuá- rios de drogas foi o questionário de comportamento de risco para AIDS (CRA), uma versão do risk assessment battery (RAB) traduzida para o português brasileiro e adaptada por Pechansky et al. (12-14). O CRA é um instrumento de fácil entendimento, foi auto-administrado na maioria dos casos e o tempo médio de preenchimento foi de 10 minutos. É composto por 22 questões que avaliam os dados demográficos do respondente, sua história de uso de drogas, seu estado sorológico para o HIV, seu comportamento sexual, suas relações envolvendo sexo, dinheiro e drogas e suas preocupações referentes à contaminação e à transmissão do HIV. O instrumento gera um escore de risco para sexo e outro para drogas; o primeiro varia de 0 a 30, e o segundo, de 0 a 24 .

$\mathrm{O}$ ingresso dos sujeitos neste estudo foi feito mediante consentimento verbal, com a finalidade de preservar a identidade dos participantes. O projeto foi aprovado pelo Conselho Estadual de Entorpecentes e pela Comissão de Ética e Pesquisa do Hospital de Clínicas de Porto Alegre.

As amostras de sangue foram testadas para anticorpos anti-HIV usando o método imunoenzimático (ELISA). Antes do exame, cada indivíduo participava de uma sessão de aconselhamento em grupo sobre HIV e AIDS, de acordo com os critérios do Ministério da Saúde do Brasil. Cada grupo tinha no máximo 20 participantes.

Após revisão, os dados coletados foram analisados utilizando-se o programa Statistical Package for the Social Sciences (SPSS) 11.0. As variáveis estudadas foram consumo de substâncias psicoativas (álcool, maconha, cocaína inalada, crack, droga injetável e inalante), variáveis demográficas (gênero, idade, renda, trabalho, situação conjugal e escolaridade) e variáveis de exposição a risco para contaminação por HIV (uso de preservativos, número de parceiros, relações sexuais envolvendo dinheiro ou drogas, parceiro sexual UDI e freqüência a lugar para uso de drogas). Os escores acima do percentil 75 para sexo e droga foram considerados como indicando risco para a transmissão do HIV e comparados com os 
escores abaixo desse ponto de corte. Algumas variáveis foram agrupadas em categorias. Para os testes de hipótese, foram utilizados o qui-quadrado $\left(\chi^{2}\right)$, o teste exato de Fisher e a razão de chances (odds ratio, OR), com nível de significância de $5 \%(P<0,05)$ e intervalo de confiança de 95\% (IC95\%). A OR ajustada foi calculada para algumas variáveis através de regressão logística. Essas variáveis foram escolhidas com base nas análises bivariadas e no modelo teórico de exposição a situações de risco proposto pelo primeiro autor (15). Foi utilizado o método retrógrado, retirando-se do modelo as variáveis que, após a análise, tinham significância menor do que 0,10 . Foram mantidas no modelo as variáveis cuja inclusão, mesmo com um $P>0,10$, era justificada pela literatura. Mesmo sendo um estudo transversal, optou-se por utilizar a OR para a estimativa de risco, para que se pudesse testar o modelo teórico proposto.

\section{RESULTADOS}

O número de indivíduos com teste positivo para HIV na amostra estudada foi de 155 , ou $15,1 \%$ do total da amostra. Dos 106 sujeitos que relataram já ter utilizado drogas injetáveis alguma vez na vida, 53 , ou $50 \%$, eram HIV-positivos.

As tabelas 1, 2 e 3 apresentam, respectivamente, dados demográficos e resultados sobre o uso de drogas e a exposição a situações de risco para a contaminação por HIV e suas associações com essa contaminação. A tabela 4 apresenta os resultados da regressão logística com variáveis selecionadas.

A amostra foi composta por uma maioria de indivíduos homens com mais de 25 anos, com renda familiar de menos de 3 salários mínimos, tendo a metade deles completado o ensino fundamental e, em sua maioria, algum tipo de trabalho (tabela 1). O salário mínimo brasileiro na época do estudo variou entre 100 e 120 reais (cerca de 100 dólares). Na análise bivariada, encontrou-se associação $(P<0,05)$ entre soropositividade e ter mais de 25 anos, ser homem, ter renda familiar inferior a 3 salários mínimos e ter no máximo ensino fundamental completo.

Na tabela 2 encontram-se as informações sobre uso de álcool e drogas nos 30 dias anteriores à coleta de dados. O uso freqüente de álcool e ter usado alguma vez maconha, cocaína inalada ou droga injetável no último mês estiveram associados $(P<0,05)$ com maior soropositividade.

A tabela 3 apresenta as situações de risco avaliadas no CRA e a sua associação com soropositividade, juntamente com os subescores do CRA para sexo e droga e sua associação com soropositividade para HIV, divididos no percentil 75. Encontrou-se associação $(P<0,05)$ com soropositividade nos indivíduos que apresentarem, nos 6 meses anteriores à entrevista, relato de mais de dois parceiros sexuais, relação sexual com indivíduo possivelmente HIV-positivo, ter freqüentado lugares específicos para uso de drogas, ter usado droga injetável alguma vez na vida e ter um subescore para drogas maior do que o percentil 75 . O resultado equivalente de subescore acima do percentil 75 para sexo obteve significância marginal, indicando uma possível tendência para associação.

Na tabela 4 encontram-se os resultados da regressão logística com as variáveis estatisticamente associadas com contaminação por HIV. Inicialmente, foram incluídas no modelo as seguintes variáveis, significativas na análise bivariada: gênero, idade, renda, escolaridade, uso de maconha,

TABELA 1. Demografia geral da amostra de clientes de centros de testagem gratuita para HIV e sua relação com soropositividade para HIV, Porto Alegre (RS), Brasil, 1995 a 1997

\begin{tabular}{|c|c|c|c|c|c|c|}
\hline \multirow[b]{2}{*}{ Característica } & \multicolumn{2}{|c|}{ Geral $^{a}$} & \multicolumn{2}{|c|}{$\begin{array}{c}\text { HIV- } \\
\text { positivos }^{b}\end{array}$} & \multirow[b]{2}{*}{$P$} & \multirow[b]{2}{*}{ OR $(\mathrm{IC} 95 \%)$} \\
\hline & No. & $(\%)$ & No. & $(\%)$ & & \\
\hline \multicolumn{7}{|l|}{ Idade } \\
\hline$<25$ anos & 390 & $(39,4)$ & 45 & $(11,5)$ & \multirow[t]{2}{*}{$<0,05$} & \multirow[t]{2}{*}{$11,6(1,1$ a 2,3$)$} \\
\hline$\geq 25$ anos & 601 & $(60,6)$ & 102 & $(17,0)$ & & \\
\hline \multicolumn{7}{|l|}{ Gênero } \\
\hline Masculino & 580 & $(56,9)$ & 106 & $(18,3)$ & \multirow[t]{2}{*}{$<0,05$} & \multirow[t]{2}{*}{$1,9(1,3$ a 2,8$)$} \\
\hline Feminino & 440 & $(43,1)$ & 46 & $(10,5)$ & & \\
\hline \multicolumn{7}{|l|}{ Renda familiar } \\
\hline$\leq 3$ salários mínimos & 601 & $(60,5)$ & 116 & $(19,3)$ & \multirow[t]{2}{*}{$<0,001$} & $2,6(1,7$ a 4,0$)$ \\
\hline$\geq 4$ salários mínimos & 392 & $(39,2)$ & 33 & $(8,4)$ & & 1 \\
\hline \multicolumn{7}{|l|}{ Escolaridade } \\
\hline Até ensino fundamental completo & 526 & $(51,4)$ & 96 & $(18,3)$ & \multirow[t]{2}{*}{$<0,05$} & $1,7(1,2$ a 2,5$)$ \\
\hline Ensino médio incompleto ou mais & 497 & $(48,6)$ & 57 & $(11,5)$ & & 1 \\
\hline \multicolumn{7}{|l|}{ Trabalho $^{c}$} \\
\hline Regular ou irregular & 809 & $(79,9)$ & 120 & $(14,8)$ & \multirow[t]{2}{*}{0,74} & 1 \\
\hline Não trabalha ou bico & 203 & $(20,1)$ & 32 & $(15,8)$ & & $1,1(0,7$ a 1,6$)$ \\
\hline
\end{tabular}


TABELA 2. Uso de substâncias psicoativas nos 30 dias anteriores à coleta e associação com soropositividade para HIV, Porto Alegre (RS), Brasil, 1995 a 1997

\begin{tabular}{|c|c|c|c|c|c|c|}
\hline \multirow[b]{2}{*}{ Utilizou } & \multicolumn{2}{|c|}{ Geral $^{a}$} & \multicolumn{2}{|c|}{$\begin{array}{c}\text { HIV- } \\
\text { positivos }^{b}\end{array}$} & \multirow[b]{2}{*}{$P$} & \multirow[b]{2}{*}{ OR $(\text { IC95\%) })^{c}$} \\
\hline & No. & $(\%)$ & No. & $(\%)$ & & \\
\hline \multicolumn{7}{|l|}{ Álcool } \\
\hline Nada/poucas vezes & 805 & $(79,7)$ & 104 & $(12,9)$ & \multirow[t]{2}{*}{$<0,05$} & 1 \\
\hline Freqüentemente & 218 & $(21,3)$ & 46 & $(21,1)$ & & $1,7(1,2$ a 2,6$)$ \\
\hline \multicolumn{7}{|l|}{ Maconha } \\
\hline Nada & 742 & $(72,8)$ & 100 & $(13,5)$ & \multirow[t]{2}{*}{$<0,05$} & 1 \\
\hline Alguma vez & 277 & $(27,2)$ & 54 & $(19,5)$ & & $1,6(1,1$ a 2,3$)$ \\
\hline \multicolumn{7}{|l|}{ Cocaína inalada } \\
\hline Nada & 828 & $(81,1)$ & 110 & $(13,3)$ & \multirow[t]{2}{*}{$<0,001$} & 1 \\
\hline Alguma vez & 193 & $(18,9)$ & 44 & $(29,5)$ & & $2,3(1,5$ a 3,5$)$ \\
\hline \multicolumn{7}{|l|}{ Droga injetável } \\
\hline Nada & 975 & $(95,6)$ & 130 & $(12,7)$ & \multirow[t]{2}{*}{$<0,001$} & 1 \\
\hline Alguma vez & 45 & $(4,4)$ & 23 & $(51,1)$ & & $6,8(3,5$ a 13,1$)$ \\
\hline \multicolumn{7}{|l|}{ Crack } \\
\hline Nada & 1000 & $(98,0)$ & 147 & $(14,7)$ & \multirow[t]{2}{*}{0,10} & 1 \\
\hline Alguma vez & 20 & $(2,0)$ & 6 & $(37,5)$ & & $2,5(0,8$ a 7,1$)$ \\
\hline \multicolumn{7}{|l|}{ Loló } \\
\hline Nada & 962 & $(94,5)$ & 138 & $(14,3)$ & \multirow[t]{2}{*}{0,07} & 1 \\
\hline Alguma vez & 56 & $(4,5)$ & 13 & $(23,2)$ & & $1,8(0,9$ a 3,6$)$ \\
\hline
\end{tabular}

TABELA 3. Exposição a situações de risco e associação com soropositividade em clientes de centros de testagem gratuita para HIV, Porto Alegre (RS), Brasil, 1995 a 1997

\begin{tabular}{|c|c|c|c|c|c|c|}
\hline \multirow[b]{2}{*}{ Situação } & \multicolumn{2}{|c|}{ Geral $^{a}$} & \multicolumn{2}{|c|}{$\begin{array}{c}\text { HIV- } \\
\text { positivos }^{b}\end{array}$} & \multirow[b]{2}{*}{$P$} & \multirow[b]{2}{*}{ OR (IC95\%) } \\
\hline & No. & $(\%)$ & No. & $(\%)$ & & \\
\hline \multicolumn{7}{|c|}{ Uso de preservativos nos últimos 6 meses } \\
\hline Sempre/quase sempre & 507 & $(50,2)$ & 77 & $(15,2)$ & \multirow[t]{2}{*}{1,0} & 1 \\
\hline Nunca/quase nunca & 502 & $(49,8)$ & 76 & $(15,2)$ & & $1,0(0,7$ a 1,4$)$ \\
\hline \multicolumn{7}{|c|}{ Parceiros sexuais nos últimos 6 meses } \\
\hline Nenhum ou um & 470 & $(50,1)$ & 84 & $(17,9)$ & \multirow[t]{2}{*}{$<0,05$} & 1 \\
\hline Dois ou mais & 468 & $(49,9)$ & 60 & $(12,8)$ & & $1,5(1,02$ a 2,2$)$ \\
\hline \multicolumn{7}{|c|}{ Relações sexuais pagas nos últimos 6 meses } \\
\hline Não & 934 & $(92,4)$ & 143 & $(15,3)$ & \multirow[t]{2}{*}{0,74} & 1 \\
\hline Alguma vez & 77 & $(7,6)$ & 10 & $(13,0)$ & & $0,8(0,4$ a 1,6$)$ \\
\hline \multicolumn{7}{|c|}{ Relações sexuais com possível HIV-positivo } \\
\hline Não & 880 & $(87,6)$ & 125 & $(14,2)$ & \multirow[t]{2}{*}{$<0,05$} & 1 \\
\hline Alguma vez & 125 & $(12,4)$ & 29 & $(23,2)$ & & $1,8(1,2$ a 2,9$)$ \\
\hline \multicolumn{7}{|c|}{ Visitou lugar para uso de drogas nos últimos } \\
\hline 6 meses & & & & & & \\
\hline Não & 832 & $(81,1)$ & 108 & $(13,0)$ & \multirow[t]{2}{*}{$<0,001$} & 1 \\
\hline Alguma vez & 194 & $(18,9)$ & 47 & $(24,2)$ & & $2,1(1,5$ a 3,2$)$ \\
\hline \multicolumn{7}{|c|}{ Usou droga injetável alguma vez na vida } \\
\hline Sim & 106 & $(10,3)$ & 53 & $(50,0)$ & \multirow[t]{2}{*}{$<0,001$} & $8,0(5,2$ a 12,4$)$ \\
\hline Não & 920 & $(89,7)$ & 102 & $(11,9)$ & & 1 \\
\hline \multicolumn{7}{|c|}{ Teve parceiro usuário de droga injetável } \\
\hline Sim & 121 & $(11,8)$ & 27 & $(22,3)$ & \multirow[t]{2}{*}{$<0,05$} & $1,7(1,1$ a 2,8$)$ \\
\hline Não & 905 & $(88,2)$ & 128 & $(14,1)$ & & 1 \\
\hline \multicolumn{7}{|c|}{ Escore droga $>$ percentil $75 \mathrm{CRA}^{\mathrm{a}}$} \\
\hline Não & 737 & $(75,5)$ & 82 & $(11,1)$ & \multirow{3}{*}{$<0,001$} & 1 \\
\hline Sim & 239 & $(24,5)$ & 62 & $(25,9)$ & & $2,8(1,9$ a 4,0$)$ \\
\hline \multicolumn{6}{|c|}{ Escore sexo $>$ percentil 75 CRA $^{a}$} & \\
\hline Não & 609 & $(67,3)$ & 82 & $(13,5)$ & \multirow[t]{2}{*}{0,07} & 1 \\
\hline Sim & 296 & $(32,7)$ & 54 & $(18,2)$ & & $1,4(0,98$ a 2,1$)$ \\
\hline
\end{tabular}

${ }^{a}$ CRA = questionário de comportamento de risco para AIDS, versão em português brasileiro do risk assessment battery (RAB). Os escores acima do percentil 75 para sexo e droga foram considerados como indicando risco para a transmissão do HIV. 
TABELA 4. Regressão logística incluindo variáveis selecionadas e soropositividade para HIV

\begin{tabular}{|c|c|c|c|}
\hline Variável & OR bruta & OR ajustada & $P$ \\
\hline \multicolumn{4}{|l|}{ Gênero } \\
\hline Masculino & $1,9(1,3$ a 2,8$)$ & $1,8(1,1$ a 2,8$)$ & $<0,05$ \\
\hline Feminino & 1 & 1 & \\
\hline \multicolumn{4}{|l|}{ Idade } \\
\hline$<25$ anos & 1 & 1 & $<0,05$ \\
\hline$\geq 25$ anos & $1,6(1,1$ a 2,3$)$ & $1,7(1,1$ a 2,7$)$ & \\
\hline \multicolumn{4}{|l|}{ Renda familiar ${ }^{a}$} \\
\hline$\leq 3$ salários mínimos & $2,6(1,7$ a 4,0$)$ & $2,1(1,3$ a 3,5$)$ & $<0,05$ \\
\hline$\geq 4$ salários mínimos & 1 & 1 & \\
\hline \multicolumn{4}{|l|}{ Escolaridade } \\
\hline Até ensino fundamental completo & $1,7(1,2$ a 2,5$)$ & $1,1(0,7$ a 1,7$)$ & 0,732 \\
\hline Ensino médio incompleto ou mais & 1 & 1 & \\
\hline \multicolumn{4}{|l|}{ Usou droga injetável alguma vez na vida } \\
\hline Não & 1 & 1 & $<0,001$ \\
\hline Sim & $8,0(5,2$ a 12,4$)$ & $7,6(4,4$ a 13,0$)$ & \\
\hline \multicolumn{4}{|c|}{ Relações sexuais com possível HIV-positivo } \\
\hline Não & 1 & 1 & $<0,05$ \\
\hline Alguma vez & $1,8(1,2$ a 2,9$)$ & $1,8(1,1$ a 3,2$)$ & \\
\hline \multicolumn{4}{|c|}{ Visitou lugar para uso de drogas nos últimos 6 meses } \\
\hline Não & 1 & 1 & 0,06 \\
\hline Alguma vez & $2,1 \quad(1,5$ a 3,2$)$ & $1,7(0,97$ a 3,0$)$ & \\
\hline \multicolumn{4}{|c|}{ Número de parceiros sexuais nos últimos 6 meses } \\
\hline Nenhum ou um & 1 & 1 & $<0,05$ \\
\hline Dois ou mais & $1,5(1,02$ a 2,2$)$ & $0,6(0,4$ a 0,9$)$ & \\
\hline
\end{tabular}

a Salário mínimo entre 100 e 120 reais (cerca de 100 dólares) na época do estudo.

cocaína e álcool nos 30 dias prévios à coleta, uso de droga injetável alguma vez na vida, freqüência a locais para uso de drogas, relação sexual com parceiro que usou droga injetável alguma vez na vida, número de parceiros sexuais nos últimos 6 meses, relação sexual com indivíduo possivelmente contaminado por HIV e escores para drogas. Após a análise, as variáveis que permaneceram significativamente associadas com contaminação foram ser homem, ter mais de 25 anos, ter renda familiar de menos de 3 salários mínimos, ter utilizado droga injetável alguma vez na vida e ter tido relação sexual com indivíduo possivelmente HIV-positivo nos 6 meses anteriores, ter freqüentado lugares específicos para uso de drogas e ter tido um ou nenhum parceiro sexual. A variável escolaridade foi mantida no modelo por estar associada na literatura com maior contaminação por HIV. Foram excluídas, por significância menor do que 0,10 , o uso de maconha, de cocaína e de álcool nos 30 dias prévios, ter tido parceiro com uso de droga injetável al- guma vez na vida e escore de drogas maior do que o percentil 75 .

\section{DISCUSSÃO}

Esta amostra apresenta o viés de ser composta por indivíduos de um estrato socioeconômico e cultural pouco favorecido e que se consideravam sob maior risco, o que restringe em parte a generalização dos dados (16-19). A percepção de risco é bastante variável entre indivíduos. Por exemplo, mulheres mais expostas a risco tendem a fazer mais testes e a retornar mais freqüentemente para buscar o resultado (11). Mesmo assim, os dados aqui relatados têm alguma representatividade para pessoas que buscam testagem para HIV, e servem para definir as características específicas da amostra estudada, podendo ser utilizados no intuito de guiar ações preventivas de saúde pública.

Com relação aos achados, parece que foi a forma de uso da droga, e não o tipo de droga em si, o que determi- nou a soropositividade da amostra. Podemos inferir também que o impacto do uso apenas eventual de uma droga nas condutas de risco não é tão pronunciado, mas que a superposição do uso de várias drogas pode ser um fator importante para diminuir o juízo crítico sobre a percepção de risco em indivíduos expostos ao HIV (20).

No que compete à soropositividade geral da amostra estudada, é chamativo que $15,1 \%$ dos indivíduos fossem soropositivos para HIV, já que o uso regular de drogas foi raro. Imagina-se que a causa principal da contaminação esteja relacionada a situações ou comportamentos de risco que envolvam sexo sem proteção-com ou sem a presença de drogas. Mesmo que os indivíduos que mencionaram ter alguma vez utilizado drogas injetáveis apresentassem mais chance de soropositividade do que os que não se injetaram, a fração total de indivíduos que utilizaram drogas injetáveis alguma vez na vida foi de apenas 10,3\% do total desta amostra, ou $34,2 \%$ dos indivíduos soropositivos. O restante da soropositividade, portanto, tem explicação pelas outras vias de contaminação. De qualquer forma, o uso de droga injetável aumentou de forma significativa (aproximadamente 8 vezes) o risco para soropositividade.

No modelo bivariado apresentado nas tabelas 1, 2 e 3, diversas variáveis mostraram-se associadas à soropositividade, o que corrobora estudos anteriores realizados por nosso grupo em Porto Alegre (4-6). Por exemplo, baixa escolaridade, gênero masculino, idade acima de 25 anos, baixa renda familiar e baixa escolaridade apresentaram associação com soropositividade. Isso pode estar refletindo aspectos históricos da epidemia de AIDS no Brasil à época da coleta (1995 a 1997): os homens eram mais expostos à epidemia do que as mulheres e eram escassas as informações sobre HIV/AIDS. De forma similar, o uso freqüente de álcool e outras substâncias esteve mais fortemente associado à soropositividade nas análises bivariadas, bem como ter injetado drogas alguma vez na vida e freqüentar locais específicos para uso de drogas. Genericamente, o 
subescore alto (acima do percentil 75) no CRA para as questões sobre droga corrobora esses achados.

No que compete às variáveis de comportamento sexual, o relacionamento com dois ou mais parceiros e as relações sexuais com indivíduo usuário de droga injetável ou potencialmente soropositivo apresentaram maior associação com soropositividade. O subescore para questões sobre sexo do CRA apresentou significância marginal nas análises bivariadas.

Entretanto, a análise dos dados por regressão logística sustentou apenas parcialmente os achados das análises bivariadas. Por exemplo, no que compete às variáveis sociodemográficas, a baixa escolaridade não apresentou uma OR significativamente associada à soropositividade. Tal fato sugere que, da combinação renda baixa/escolaridade baixa, encontrada em diversos estudos realizados pelo grupo, é a renda que determina uma maior propensão à soropositividade. Dessa forma, o custo de proteger-se contra a infecção pelo HIV ainda pesa na balança da prevenção.

Em conclusão, os elementos que são componentes da regressão logística apresentada na tabela 4 podem ser corroborados por um modelo teórico de exposição a risco para HIV em usuários de drogas, já previamente publi- cado por um dos autores (15). Nesse modelo, a informação, a escolaridade, o gênero e a idade direcionam atitudes associadas ao uso de drogas e à percepção do risco envolvido, gerando um efeito em cascata que culmina no aumento da chance de contaminação por parte desses indivíduos. Diferentemente do modelo proposto em 2001, que considerava o uso sistemático ou regular de substâncias como elemento de risco para a contaminação, é possível conceber que o uso eventual —em algumas circunstâncias em apenas um episódio- possa acarretar modificações semelhantes às causadas pelo uso regular no comportamento de risco para HIV. Essas condutas tendem a aumentar sistematicamente o risco de contaminação e transmissão do HIV de indivíduo para indivíduo, particularmente dentro de sua rede social (21, 22). É possível que um grande número de variáveis individuais, mas que ajam em conjunto, anulando-se ou potencializando-se, tais como o grau de escolaridade, o gênero, a idade e muitas outras, acarretem um maior número de condutas ou situações de risco.

Mesmo que, de forma isolada, injetarse ou compartilhar drogas contribua de forma significativa para a aquisição e a transmissão do HIV, é possível, a partir dos achados do estudo, identificar um cenário onde usuários injetáveis de cocaína —eventuais ou não, de baixa renda e conseqüentemente expostos a um nível menor de informação- carreguem de forma mais intensa o peso de distribuição da epidemia em nosso meio. Independentemente de serem uma fração dos casos totais, já existem abordagens preventivas para esse tipo de indivíduo na rede comunitária de saúde de nosso País, com destaque para os programas de redução de danos. A partir daí, como recomendação principal, os autores sugerem a construção e a testagem de intervenções preventivas - no caso, voltadas para usuários recreacionais de substâncias que buscam centros de testagem - com o intuito de diminuir a exposição ao vírus HIV. Mais ainda, a monitoração constante dos casos atendidos pelos programas de redução de danos, em particular os que envolvem troca de seringas e contato direto com usuários injetáveis em seu habitat natural, pode auxiliar na compreensão da dinâmica da epidemia em nosso meio, gerando soluções mais adequadas a essa fração da população exposta ao HIV.

Agradecimentos. Este estudo foi parcialmente financiado pelo Center for Drug and Alcohol Studies, University of Delaware, Newark, Estados Unidos.

\section{REFERÊNCIAS}

1. UNAIDS. AIDS epidemic in Latin America fact sheet. UNAIDS: 2004. Disponível em: http: / / www.unaids.org/html/pub / publications/fact-sheets04/FS_Brazil 24Jul05_en_pdf/FS_Brazil_24Jul05. Acessado em agosto de 2005.

2. Brasil, Ministério da Saúde. Tabela V-Taxa de incidência (por 100000 hab.) de AIDS segundo faixa etária por sexo e ano de diagnóstico. Brasil (1980-2003). Boletim Epidemiológico AIDST. 2004;I(1):30. Disponível em http:// www.aids.gov.br/final/dados/BOLETIM2. pdf . Acessado em agosto de 2005.

3. Brasil, Ministério da Saúde. Tabela I-Casos de AIDS segundo UF e região de residência por ano de diagnóstico. Brasil, 1980-2004. Boletim Epidemiológico AIDST. 2004;I(1):26. Disponível em http:/ / www.aids.gov.br/final/ dados/BOLETIM2.pdf. Acessado em agosto de 2005.

4. Pechansky F, Von Diemen L. Homens e mulheres usuários de drogas: semelhanças e dife- renças na exposição ao vírus HIV em Porto Alegre. Rev ABEAD. 1999;1(2):15-25.

5. Pechansky F, Von Diemen L, Genro V. Presença de situações de risco para a transmissão do HIV em usuários de drogas não injetáveis. Rev Psiquiatr Clin. 2001;28(3):157-9.

6. Pechansky F, Inciardi J, Surratt H, Lima AF, Kessler F, Soibelman M, Hirakata, V. Um estudo exploratório sobre as características de usuários de drogas injetáveis que buscam atendimento em Porto Alegre. Rev Bras Psiquiatr. 2000;22(4):164-71.

7. Carlini EA, Galduroz JCF, Noto AR, Nappo S, eds. I levantamento domiciliar sobre o uso de drogas psicotrópicas no Brasil. Centro Brasileiro de Informação sobre Drogas Psicotrópicas. São Paulo: Secretaria Nacional AntiDrogas (SENAD)/Gabinete de Segurança Institucional da Presidência da República; 2002.

8. Brasil, Ministério da Saúde. Gráfico 1.1Casos de AIDS, segundo as principais cate- gorias de exposição e ano de diagnóstico. Brasil, 1980-2003. Boletim Epidemiológico AIDS. 2003;XVII(1):37. Disponível em http:/ / www. aids.gov.br/final/biblioteca/boletim_dezembro 2003/graficola.asp. Acessado em agosto de 2005.

9. Watkins KE, Metzger DS, Woody GE. Highrisk sexual behaviors of intravenous drug users in and out-of-treatment: implications for the spread of HIV infection. Am J Drug Alcohol Abuse. 1992;18(4):389-98.

10. WHO Collaborative Study Group. An international comparative study of HIV prevalence and risk behavior among drug injectors in 13 cities. Bull Narc. 1993;45(1):19-46.

11. Solomon L, Moore J, Gleghorn A, Astemborski J, Vlahov D. HIV testing behaviors in a population of inner-city women at high risk for HIV infection. J Acquir Immune Defic Syndr Human Retrovirol. 1996;13(3):267-72.

12. Metzger DS, Woody G, McLellan AT, O'Brien $\mathrm{CP}$, Navaline H. Twenty-four month serocon- 
version rates and behavioral change among injection drug users in and out-of-treatment. Em: National Institute on Drug Abuse (NIDA). Proceedings of the Community Epidemiology Work Group. Filadélfia: NIDA; 1992. Pp. 503-6.

13. Metzger DS. The risk assessment battery (RAB): validity and reliability [relatório]. Sixth Annual Meeting of the National Cooperative Vaccine Development Groups for AIDS. Alexandria: National Institute of Allergy and Infectious Diseases; 1993.

14. Pechansky F, Metzger D, Hirakata V. Adaptation and validation of a questionnaire about risk behaviors for AIDS among drug users. Rev Bras Psiquiatr. 2002;24(3):130-6.

15. Pechansky F. Modelo teórico de exposição a risco para transmissão do vírus HIV em usuários de drogas. Rev Bras Psiquiatr. 2001;23(1): 39-45.

16. Murphy D, Mitchell R, Vermund SH, Futterman D. Factors associated with HIV testing among HIV-positive and HIV-negative high risk adolescents: The REACH study. Pediatrics. 2002;110(3):e36.

17. Miller KS, Hennessy M, Wendell DA, Webber MP, Schoenbaum EF. Behavioral risks for HIV infection associated with HIV testing decisions. AIDS Educ Prev. 1996;8(5);394-402.

18. Fernyak SE, Page-shafer K, Kellogg TA, McFarland W, Katz MH. Risk behaviours and HIV incidence among repeat testers at publicly funded HIV testing sites in San Francisco. J Acquir Immune Defic Syndr. 2002; 31(1):63-70.

19. Renzi C, Zantedeschi E, Signorelli C, Osborn JF. Factors associated with HIV testing: results from an Italian General Population Survey. Prev Med. 2001;32(1):40-8.

20. Pechansky F, Von Diemen L, Kessler F, Hirakata V, Metzger D, Woody G. Preliminary estimates of human immunodeficiency virus prevalence and incidence among cocaine abusers of Porto Alegre, Brazil. J Urban Health. 2003;80(1):115-26.

21. Latkin C. A personal network approach to AIDS prevention: an experimental peer group intervention for street-injecting drug users: the SAFE study. Em: Needle R, Genser SG, Trotter RT, eds. Social networks, drug abuse, and HIV transmission-NIDA Research Monograph 151. Bethesda: National Institute on Drug Abuse; 1995. Pp. 181-95.

22. Latkin C, Mandell W, Vlahov D, Knowlton A, Oziemkowska M, Celentano D. Personal network characteristics as antecedents to needlesharing and shooting gallery attendance. Social Networks. 1995;17(3-4):219-28.

Manuscrito recebido em 27 de setembro de 2004. Aceito em versão revisada em 2 de agosto de 2005.

ABSTRACT Objective. To describe substance use, HIV seroprevalence, and risk of exposure to HIV infection in individuals seeking HIV testing in two screening centers (a municipal one and a state one) in the city of Porto Alegre, Rio Grande do Sul, Brazil.

Substance use, risk situations, and HIV seroprevalence among individuals seeking free HIV testing in Porto Alegre, Brazil
Methods. Using a cross-sectional design, we enrolled a convenience sample of 1026 men and women between 15 and 60 years of age. We included all the subjects who, after an initial triage, reported any drug use or any behavior or situation with risk of HIV transmission. A Brazilian-Portuguese version of the Risk Assessment Battery was used to assess exposure to risk situations. Blood samples were tested for anti-HIV antibodies, using enzyme-linked immunosorbent assay. Before the blood test, individuals participated in a group counseling session (with a maximum of 20 participants) on HIV and AIDS, in line with the criteria of the Ministry of Health of Brazil. Results. Among the sample, a high overall HIV seroprevalence was found, $15.1 \%$. Drug use did not explain all of the risk exposure. In comparison to those who reported no injecting drug use, the odds ratio (OR) for being HIV-positive for those who reported injecting drug use at some point in their life was 7.6 (95\% confidence interval $(\mathrm{CI})=4.4$ to 13.0 ). However, only $10.3 \%$ of the sample reported any injecting drug use. The variables that were associated with HIV seropositivity were: male gender (OR = $1.8 ; 95 \% \mathrm{CI}=1.1$ to 2.8$)$, monthly family income below three times the minimum-salary amount $(\mathrm{OR}=2.1 ; 95 \% \mathrm{CI}=1.3$ to 3.5$)$, age over $25(\mathrm{OR}=1.7 ; 95 \% \mathrm{CI}=1.1$ to 2.7$)$, and having had sexual relations with a partner who was possibly HIV-positive $(\mathrm{OR}=1.8$; $95 \% \mathrm{CI}=1.1$ to 3.2 ).

Conclusions. Even irregular or occasional drug use increases the odds of seropositivity, particularly if intravenous drugs are used. Sexual transmission played an important role in seropositivity in this sample, indicating that drug use can affect the judgment of risk and thus contribute to HIV transmission.

Key words Substance abuse, intravenous; epidemiology; acquired immunodeficiency syndrome. 